\title{
REVIEW ARTICLE \\ Meningococcal disease in Asia: an under-recognized public health burden
}

\author{
A. VYSE ${ }^{1 *}$, J. M. WOLTER ${ }^{2}$, J. CHEN ${ }^{1}$, T. NG ${ }^{1}$ And M. SORIANO-GABARRO ${ }^{1}$ \\ ${ }^{1}$ GlaxoSmithKline Biologicals Group of Companies, Wavre, Belgium \\ ${ }^{2}$ Independent Consultant, Brisbane, Australia
}

(Accepted 9 March 2011; first published online 15 April 2011)

\section{SUMMARY}

A literature search traced existing information on meningococcal disease in Asia. Reviewed data describing the epidemiology of meningococcal disease in Asia are incomplete, due in part to absence of surveillance in many countries, poor bacterial detection methods and social and healthcare barriers to disease reporting. This suggests that meningococcal disease in some Asian countries may be under-recognized, with a need to introduce/improve existing surveillance and case identification systems. Nevertheless, in some developing Asian countries, the disease burden may be significant. Serogroup A meningococcal epidemics are responsible for high morbidity and mortality in some countries and continue to be an ongoing threat, particularly in developing countries. There is an increasing role played by serogroups $\mathrm{C}, \mathrm{Y}$, and $\mathrm{W}-135$ in invasive disease, indicating evolving meningococcal disease epidemiology in some countries. Multivalent meningococcal conjugate vaccines offer new opportunities in the region for reducing the meningococcal disease burden.

Key words: Asia, epidemic, epidemiology, meningococcal meningitis, meningococcal infection, morbidity, mortality, Neisseria meningitidis, vaccination.

\section{INTRODUCTION}

Despite appropriate antibiotic and supportive therapy, invasive disease due to Neisseria meningitidis results in death in around $10 \%$ of cases. Higher mortality rates are often observed in developing countries and during epidemics [1]. The majority of invasive meningococcal disease globally is caused by $N$. meningitidis serogroups $\mathrm{A}, \mathrm{B}, \mathrm{C}, \mathrm{W}-135$, and $\mathrm{Y}$. Serogroup C and combined serogroups A, C, W-135, and $\mathrm{Y}(\mathrm{ACWY})$ conjugate vaccines are now available. Better understanding of the burden of meningococcal disease in individual countries will guide

\footnotetext{
* Author for correspondence: Dr A. Vyse, GlaxoSmithKline Biologicals, 20 Av. Fleming, 1300 Wavre, Belgium.

(Email: andrew.x.vyse@gskbio.com)
}

next-generation vaccine development and allow accurate assessment of the potential impact of such vaccines if introduced into vaccination calendars. This information will assist health policy-makers and healthcare professionals in allocating healthcare resources to maximize medical benefit to the population.

More than one-half of the world's population resides in Asia [2], a region characterized by densely populated countries and socioeconomic, geographic and ethnic diversity. The epidemiology of meningococcal disease in much of Asia is incompletely understood, but is likely to be diverse [3]. N. meningitidis serogroup $\mathrm{A}$ and $\mathrm{C}$ outbreaks are occasionally reported to the World Health Organization (WHO) Regional Office in Asia, or to national authorities.

The online version of this article is published within an Open Access environment subject to the conditions of the Creative Commons

Attribution-NonCommercial-ShareAlike licence <http://creativecommons.org/licenses/by-nc-sa/2.5/ $>$. The written permission of

Cambridge University Press must be obtained for commercial re-use. 
Anecdotal reports suggest that a considerable number of meningococcal cases may be misdiagnosed or under-reported. This review examined the available published literature and national infectious disease surveillance websites or reports where available. The aims of the review were to collate and summarize any existing information on the epidemiology of disease due to $N$. meningitidis in Asia, including GAVI (Global Alliance for Vaccines and Immunization)eligible countries in the region, and to raise awareness about meningococcal disease in Asia, highlighting the current knowledge gap.

\section{METHODS}

This review attempted to utilize all publicly available information relevant to the region pertaining to meningococcal disease. A literature search using PubMed was conducted. The search terms were '(meningococcal $O R$ Neisseria meningitidis $O R$ meningitis) $A N D$ Asia'. Secondary searches were performed by replacing 'Asia' with one of 20 specific Asian country names (China, India, Pakistan, Bangladesh, Sri Lanka, the Philippines, Japan, Indonesia, Singapore, Malaysia, Thailand, Taiwan, Vietnam, Cambodia, Laos, Mongolia, Myanmar, Hong Kong, Republic of Korea, Nepal). The search was limited to human studies. No restriction on publication year was applied. Englishand non-English-language literature and publications were assessed for relevance by review of abstracts when available. Additional references were obtained by examination of citations in published papers. Central and regional WHO websites were searched for outbreak and epidemic information. ProMED was searched (search term 'meningitis') and websites from local Ministries of Health and Centres for Disease Control were also accessed. In view of the incomplete nature of the data, papers were not assessed using quality criteria but were included if they held any information on meningococcal disease in the region.

\section{Background to meningococcal disease in the region}

A summary of all studies identified in this review is provided in Supplementary Tables S1 and S2 (available online). We found few studies that specifically evaluated meningococcal disease epidemiology in Asia. Most data came from (a) descriptions of outbreaks (a localized cluster of cases) or epidemics (widespread outbreaks of larger magnitude); (b) incidental detection of $N$. meningitidis during the course of studies designed to assess the burden of a different pathogen: typically Haemophilus influenzae type B (Hib) and Streptococcus pneumoniae; (c) hospital-based prospective and retrospective studies assessing overall meningitis disease burden, treatment or outcome.

Official statistics were difficult to obtain. Mandatory meningococcal surveillance systems appear to operate only in Japan, Hong Kong, Korea, the Philippines, Singapore, Thailand and Taiwan, all of which rely on passive reporting. In Japan only culture-confirmed cases are required to be notified. The quality of the surveillance in these countries was difficult to judge from the available information. The lack of attention to the disease may be due to other healthcare issues and the perception that the disease is rare in much of Asia $[4,5]$.

$N$. meningitidis is fastidious, susceptible to cold and drying, and culture is frequently unsuccessful. Antibiotics given prior to cerebrospinal fluid (CSF) collection significantly increase the number of negative cultures [6,7]. The technical challenges, as well as widespread availability of antibiotics (obtained 'over the counter' or by prescription) were identified by investigators as hampering attempts to describe meningococcal disease in Asia [6-9]. Economic constraints, lack of after-hours laboratory facilities, lack of laboratory expertise in detecting $N$. meningitidis and lack of available techniques aside from Gram stain and culture were also identified as obstacles to successful $N$. meningitidis identification $[10,11]$. Use of polymerase chain reaction (PCR) detection techniques increases the sensitivity of detection of $N$. meningitidis, particularly in patients who have received antibiotics [12], but these techniques have been largely unavailable on a routine basis in much of Asia. The percentage of CSF or blood samples in which no bacteria could be identified was generally high in all studies we reviewed and appeared to increase over time, an observation attributed by some authors to increasing access to antibiotics.

Social and economic obstacles to investigation of meningococcal disease were also evident. In a retrospective hospital review of 435 meningitis cases in Malaysia, lumbar puncture was performed in only 71 $(16 \cdot 3 \%)$ children due to widespread belief in the local population that lumbar puncture leads to later paralysis or impotence [13]. In Pakistan, it is estimated that only $50 \%$ of children with meningitis may reach hospital [14]. Given all these considerations, it seems likely that meningococcal infections were underdiagnosed in the majority of studies we reviewed. 
Since reliance on culture confirmation may substantially underestimate meningitis cases due to N. meningitidis for the reasons given above, we considered positive bacteriological identification present if an organism was identified in CSF or blood culture specimens using any identification technique, i.e., Gram stain, culture, latex agglutination, counter-electrophoresis or PCR.

\section{THE BURDEN OF DISEASE IN GAVI-ELIGIBLE COUNTRIES IN ASIA}

At the time of writing 11 of the 20 Asian countries we investigated (India, Pakistan, Bangladesh, Indonesia, Vietnam, Cambodia, Laos, Mongolia, Myanmar, Sri Lanka, Nepal), representing a total population of about 2 million [15], were eligible for funding from the GAVI Alliance [16]. All 11 countries currently receive GAVI support. Six of these countries (India, Indonesia, Mongolia, Nepal, Pakistan, Vietnam) have suffered major serogroup A (or C in Vietnam) meningococcal epidemics in the last 30 years (Table 1). Available data suggest that these poorer countries represent a disproportionately high fraction of the overall meningococcal disease burden in Asia. The population incidences of meningococcal disease in countries with available data are given in Table 2. Serogroup distributions by country are given in Figure 1. While some published data were available for GAVI-eligible countries, these were limited and of varying quality.

\section{Bangladesh}

Many sick children are not brought to hospital and die at home in Bangladesh [17], suggesting that meningococcal disease cases are likely to be undetected. Five studies were identified during this review. Results from four retrospective hospital-based studies conducted between 1982 and 1994 [49-52], showed N. meningitidis present in up to $35 \%(28 / 79)$ of positive cultures in all ages, and up to $18 \%$ in children aged $<2$ years with bacterial meningitis. In 48 meningococcal-positive CSF specimens between 1987 and 1994 in children aged $<5$ years, $33(69 \%)$ were from children aged $<12$ months [49].

More recently, of 628 blood and CSF samples sent to the International Centre for Diarrhoeal Disease Research in Bangladesh between 1999 and 2006, $N$. meningitidis was detected in $24.8 \%(n=136)$, of which $97.7 \%$ were serogroup A [17]. Almost $60 \%$ of cases occurred in 6- to 24-year-olds, $20 \cdot 6 \%$ occurred in 25 - to 39 -year-olds, $7 \cdot 4 \%$ in 1 - to 5 -year-olds and $2.9 \%$ of cases were in children aged $<1$ year. Between 2002 and 2004 a higher number of samples were processed by the laboratory compared to previous years. Isolation rates of other bacteria did not change over this time. However, the percentage of $N$. meningitidis positive isolates in 2002-2004 was 15 times higher than in 1999-2000, suggesting that local serogroup A outbreaks had occurred. The number of $N$. meningitidis cases then decreased over 2005 and 2006, suggesting that this was not a spurious result linked to improved detection or awareness.

In 2009 an unpublished outbreak of meningococcal disease (serogroup unconfirmed) was reported (ProMED) to have spread from India to the Chittagong Hill Tracts of Bangladesh [53, 54]. Morbidity and mortality data were not retrievable.

\section{India}

\section{Epidemic meningococcal disease}

India has experienced repeated meningococcal serogroup A epidemics over the last century [8], most recently in 2005 in Delhi and surrounding districts. Between March and July 2005, 444 cases and 62 deaths [case-fatality rate (CFR) 16.9\%] were recorded [55]. The majority of cases (44\%) and deaths (62\%) were in adolescents and young adults aged between 15 and 29 years, and $71 \%$ of those affected were males [21]. The peak attack rate in Delhi was 13·23/100 000 [56]. Serogroup A disease re-appeared in Delhi in between January and March 2006, with 177 cases reported (CFR 9.6\%) [20].

Other unpublished reports (ProMED) describe suspected meningococcal outbreaks in the regions of Nawada (2000) [57] and Meghalay, Tripura and Mizoram (2009, thought to be serogroup A), with more than 2000 cases and 257 deaths reported in 2008-2009 [54, 58, 59].

\section{Endemic meningococcal disease}

The burden of meningococcal disease between outbreaks in India is difficult to quantify. Studies in nonoutbreak settings performed since 1990 have detected little meningococcal disease [7, 60-66], but very low bacterial detection rates in many studies, considered to be the result of both technical laboratory aspects and high levels of antibiotic use prior to hospitalization (up to $79 \%$ in one study [63]), have prevented firm conclusions [7, 8]. In a 10-year retrospective 
Table 1. Meningococcal epidemics in Asian countries

\begin{tabular}{|c|c|c|c|c|c|c|}
\hline Country & Year of epidemic & Serogroup & Cases & CFR & Rate per 100000 & Ref. \\
\hline \multicolumn{7}{|l|}{ Cambodia } \\
\hline \multirow[t]{4}{*}{ China } & 1984 & A & & & $11 \cdot 7$ & [18] \\
\hline & 1977 & A & & $\sim 5 \%$ & 59 & [19] \\
\hline & 1967 & $\mathrm{~A}^{*}$ & 3 million & $\sim 6 \%$ & $150-800$ & [19] \\
\hline & 1959 & $\mathrm{~A}^{*}$ & & $\sim 10 \%$ & $\sim 55$ & [19] \\
\hline Hong Kong & 1918 & - & & & & [19] \\
\hline \multirow[t]{4}{*}{ India } & 2006 & A & 177 & $9 \cdot 6 \%$ & & [20] \\
\hline & 2005 & A & 426 & $13 \cdot 6 \%$ & $13 \cdot 23$ & [21] \\
\hline & 1985 & A & 6133 & $13 \%$ & & [22] \\
\hline & 1966 & $A^{*}$ & 616 & $20 \cdot 9 \%$ & & [22] \\
\hline \multicolumn{7}{|l|}{ Indonesia } \\
\hline \multicolumn{7}{|l|}{ Japan } \\
\hline \multicolumn{7}{|l|}{ Korea } \\
\hline \multicolumn{7}{|l|}{ Laos } \\
\hline \multicolumn{7}{|l|}{ Malaysia } \\
\hline \multirow[t]{4}{*}{ Mongolia } & 1994-95 & A & 1754 & $9 \cdot 3-12 \cdot 4 \%$ & 90 (overall) & [23] \\
\hline & & & & & 179 (capital city) & [23] \\
\hline & & & & & 359 (2-18 yr) & [23] \\
\hline & 1973-74 & $A$ or $B$ & & & $704(<9 \mathrm{yr})$ & [24] \\
\hline \multicolumn{7}{|l|}{ Myanmar } \\
\hline \multirow[t]{2}{*}{ Nepal } & 1982-84 & A & 1475 & $7-9 \%$ & 103 (overall) & [25] \\
\hline & & & & $26 \%$ & $221(<1 \mathrm{yr})$ & [25] \\
\hline Pakistan & 1988 & A & 112 & $11 \%$ & & [26] \\
\hline Philippines & 2004-2005 & A & 98 & $33 \%$ & & [27] \\
\hline \multicolumn{7}{|l|}{ Singapore } \\
\hline \multicolumn{7}{|l|}{ Sri Lanka } \\
\hline \multirow[t]{2}{*}{ Taiwan } & 1933-46 & A & & & & [28] \\
\hline & 1919-26 & A & & & & [28] \\
\hline \multicolumn{7}{|l|}{ Thailand } \\
\hline Vietnam & 1977-79 & $\mathrm{C}$ & & $27 \cdot 4-34 \cdot 7 \%$ & $>20$ & [29] \\
\hline
\end{tabular}

CFR, Case-fatality rate.

Shaded areas indicate none reported/no data.

* Serogroup unconfirmed.

review of acute bacterial meningitis cases in a tertiary hospital in Bangalore, N. meningitidis accounted for only $1.4 \%$ of microbiologically proven cases [62]. All cases occurred in individuals aged $>12$ years. In Delhi between the non-epidemic years 2002 and 2004, 971 meningococcal cases with 118 deaths (CFR 12\%) were reported [64].

$N$. meningitidis serogroup A is most commonly isolated in India but serogroup B [67] and serogroup $\mathrm{C}[68]$ also play a role in sporadic disease cases.

\section{Indonesia}

Six reports were identified that included a WHO report, and five studies that described meningitis aetiology or treatment in Indonesia [69-74]. Between 1995 and 1996, N. meningitidis was identified as the cause of meningitis in $16 \cdot 7 \%(1 / 6)$ of bacteriologically confirmed cases in children aged $<5$ years [69]. In a population-based study between 1998 and 2002 of Hib vaccination in 818 hamlets encompassing 744000 individuals, $N$. meningitidis was detected in $3 / 17$ $(17 \cdot 6 \%)$ culture-positive meningitis cases in children aged $<2$ years [70]. In 30/47 (63\%) cases of probable bacterial meningitis the causative organism could not be identified, probably due to the high previous antibiotic use and technical aspects related to sample storage [70]. During 2000, 14 cases of meningococcal meningitis with six deaths ( $43 \%$ mortality) were reported to the WHO in Indonesia [71]. Serogroup B was detected in one individual.

\section{Mongolia}

Five publications were identified: four described past epidemics and one was a prospective study of 
Table 2. Rate of meningococcal disease per 100000 population in countries with available data (non-outbreak settings)

\begin{tabular}{|c|c|c|c|c|}
\hline Country & Years studied & Age & Baseline rate per 100000 & Ref. \\
\hline \multirow[t]{14}{*}{ China } & 2003-2007 & Overall & 2.09 (Hefei) & [30] \\
\hline & Before 2003 & Overall & $0 \cdot 18$ (Hefei) & {$[30]$} \\
\hline & 2005 & Overall & $0 \cdot 18-0 \cdot 2$ & [31] \\
\hline & $2000-2002$ & Overall & $0 \cdot 25$ (Nanning) & [32] \\
\hline & 1989 & Overall & $1 \cdot 22$ & [18] \\
\hline & 1988 & Overall & 1.97 & [18] \\
\hline & 1987 & Overall & $3 \cdot 21$ & [18] \\
\hline & 1986 & Overall & $7 \cdot 56$ & [18] \\
\hline & 1985 & Overall & $10 \cdot 73$ & [18] \\
\hline & 1984 & Overall & 11.69 & [18] \\
\hline & 1983 & Overall & $7 \cdot 81$ & [18] \\
\hline & 1982 & Overall & $8 \cdot 65$ & [18] \\
\hline & 1981 & Overall & $13 \cdot 21$ & [18] \\
\hline & 1980 & Overall & $23 \cdot 44$ & [18] \\
\hline Hong Kong & 1984-1993 & $\leqslant 24 \mathrm{~m}$ & $\leqslant 0 \cdot 24 / 13 \cdot 0^{*}$ & [33] \\
\hline Japan & 1980-current & Overall & $<0.02 \dagger$ & [34] \\
\hline \multirow[t]{3}{*}{ Korea } & 2004-2008 & Overall & $0 \cdot 002-0.017 \dagger$ & [35] \\
\hline & 2002-2003 & Overall & $0.06-0.08 \dagger$ & {$[36]$} \\
\hline & $2000-2001$ & $\begin{array}{l}\text { Not specified } \\
\text { (Army recruits) }\end{array}$ & $2 \cdot 2$ & [39] \\
\hline \multirow[t]{2}{*}{ Mongolia } & 2002-2005 & $<5 \mathrm{yr}$ & 13 & [37] \\
\hline & 1971 & Overall & 17 & [24] \\
\hline \multirow[t]{5}{*}{ Philippines } & 2004 & Overall & $0 \cdot 04$ & {$[38]$} \\
\hline & 2005 & Overall & $0 \cdot 1$ & {$[38]$} \\
\hline & 2006 & Overall & $0 \cdot 03$ & [38] \\
\hline & 2007 & Overall & $0 \cdot 02$ & [38] \\
\hline & 2008 & Overall & $0 \cdot 0$ & {$[38]$} \\
\hline \multirow{2}{*}{ Singapore } & 2005-2009 & Overall & $0 \cdot 11-0.23 \dagger$ & {$[40]$} \\
\hline & $2000-2001$ & $\begin{array}{l}\text { Not specified } \\
\text { (Hajj pilgrims) }\end{array}$ & 25 & [41] \\
\hline \multirow[t]{3}{*}{ Taiwan } & 2001 & Overall & $0 \cdot 19$ & {$[42,43]$} \\
\hline & 2000 & Overall & $0 \cdot 07$ & [42] \\
\hline & 1991 & Overall & $0 \cdot 22$ & [28] \\
\hline \multirow{6}{*}{ Thailand } & 2008 & Overall & $0 \cdot 02$ & [44] \\
\hline & & $<5 \mathrm{yr}$ & $0 \cdot 10$ & [44] \\
\hline & 2007 & Overall & $0 \cdot 05$ & [44] \\
\hline & & $<5 \mathrm{yr}$ & $0 \cdot 30$ & [44] \\
\hline & 2000-2001 & $<5 \mathrm{yr}$ & 1.8 & [45] \\
\hline & 1981-1990 & Overall & $\leqslant 0 \cdot 2$ & [46] \\
\hline \multirow[t]{3}{*}{ Vietnam } & Pre-epidemic & Overall & $<5$ & [29] \\
\hline & $2000-2002$ & $<5 \mathrm{yr}$ & $2 \cdot 6$ & [47] \\
\hline & & $7-11 \mathrm{mo}$. & $21 \cdot 8$ & [47] \\
\hline
\end{tabular}

* Rate in Chinese and Vietnamese communities respectively.

$\dagger$ Calculated using the UN 2008 Revision Population Database [15] (median variant).

meningitis aetiology. Large meningococcal serogroup A epidemics originating in China spread to Mongolia in 1973-1974 and 1994-1995 [75, 76]. During the 1994-1995 epidemic, the overall attack rate ranged between 80 and $>90 / 100000$, but reached $179 /$ 100000 in the capital city of Ulaanbaator [23]. The highest incidence was in children aged between 2 and 18 years (attack rate 359/100000) [23]. The fatality rate was $7-9 \%$, with 122 deaths, and 165 deaths in the first 4 months of 1994 and 1995, respectively [23].

Little is known about the epidemiology of endemic disease in Mongolia. The estimated incidence rate during the 1970s non-epidemic period was about 10/100000 population [24]. A prospective hospitalbased study conducted between 2002 and 2005 in 


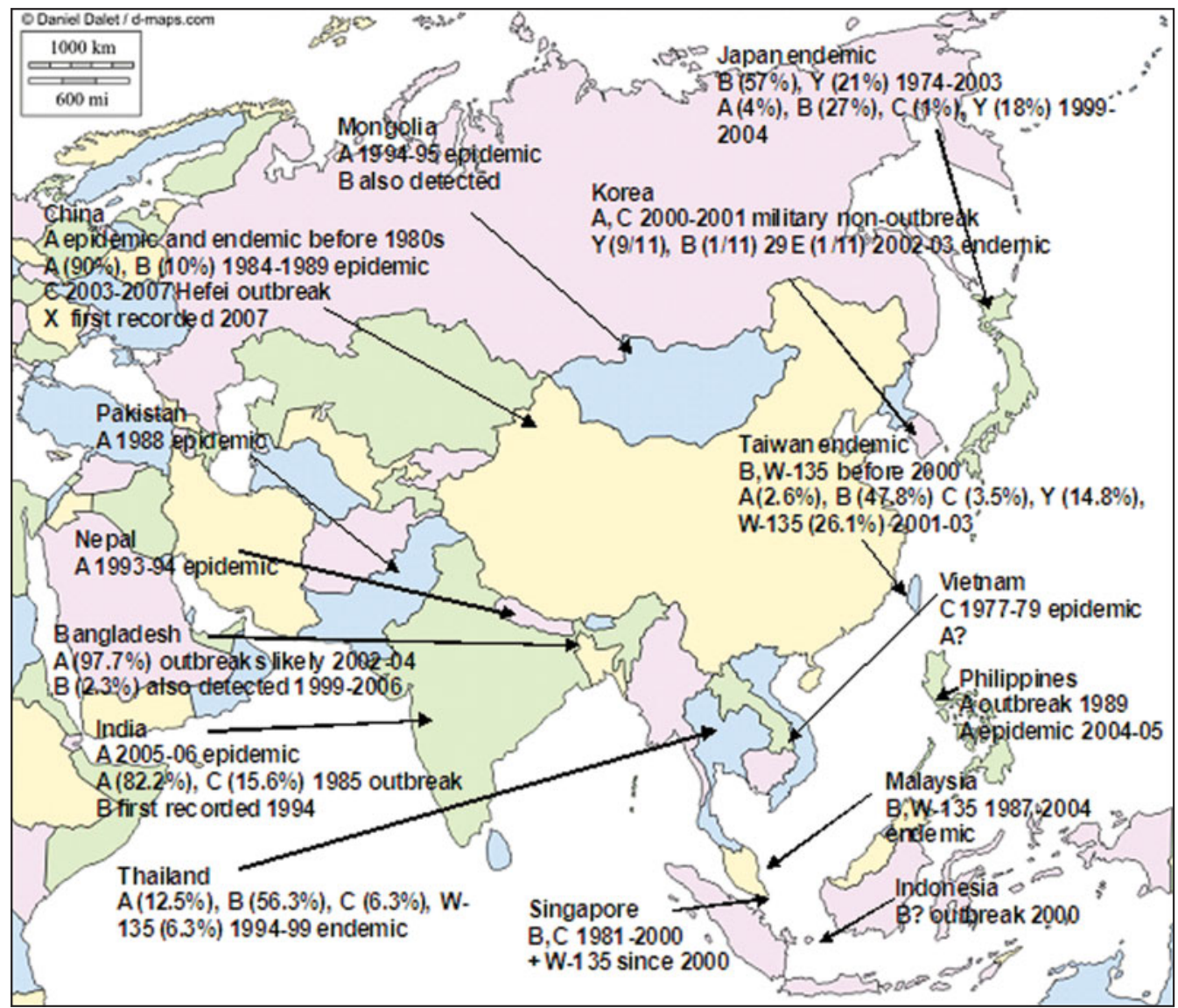

Fig. 1. Serogroup distribution of meningococcal disease cases in Asian countries with available data (map outline reproduced from [48]). $\%=$ percentage of serogroupable isolates.

Ulaanbaator identified $N$. meningitidis in $25 / 111$ $(23 \%)$ of children aged 2 month to 5 years with confirmed bacterial meningitis, giving a populationbased incidence of $13 / 100000$ [37]. Mortality was $12 \%$ [37].

\section{Myanmar}

A single brief report from the WHO indicated that during 1995, 479 cases of meningococcal disease were reported in Myanmar, with 113 deaths (CFR $24 \%$ ) [77].

\section{Nepal}

Epidemic meningococcal disease was not reported in Nepal until 1982 when a large meningococcal serogroup A outbreak occurred in the Kathmandu Valley with an overall attack rate of 103/100 000 [25, 75, 77]. Incidence and mortality was highest in infants aged $<1$ year $(221 / 100000$ and $26 \%$, respectively).
Incidences in other age groups were 104/100000 (CFR 19\%) in the 1-4 years age group, 141-156/ 100000 (CFR 6-12\%) in the 5-9, 10-14 and 15-19 years age groups, and between 32 and 95/100000 (CFR 5-16\%) in adults [25]. After resolution of the epidemic, meningococcal disease continued to be reported in tourists, primarily hikers, with an attack rate in 1985 of 19/100 000 [78].

Three studies of meningitis aetiology or treatment were identified. A single prospective study performed in a children's hospital in Kathmandu during 1993 and 1994 showed that $N$. meningitidis accounted for $26 \%(6 / 23)$ of pyogenic meningitis cases in those aged 5 months to 5 years [79]. In two prospective hospital-based studies between 2001 and 2007, $N$. meningitidis accounted for $5 \cdot 4 \%$ (2/37 bacteriologically confirmed cases) of bacterial meningitis in all age groups [80], and 2/151 (1.3\%) culture-positive meningitis cases in the $<5$ years age group, of whom $26.7 \%$ of the 151 individuals had received prior antibiotics [81]. 


\section{Pakistan}

A meningococcal serogroup A epidemic occurred in Karachi, Pakistan, in 1988 [26] with 112 cases of which $20 \%$ had septicaemia and $80 \%$ had meningococcal meningitis. Children aged between 5 and 10 years were primarily affected. Overall mortality was $11 \%$ but reached $55 \%$ in individuals with meningococcaemia.

Bacterial meningitis has been described as a major health problem in Pakistan [10]. Four studies conducted prior to 2002 suggested that over $30 \%$ of bacterial meningitis in adults and $20 \%$ in children was attributable to $N$. meningitidis $[10,82-84]$. In both children [82] and adults [10], N. meningitidis was the second most common cause of bacterial meningitis after Hib and pneumococcus, respectively. In contrast, in a prospective hospital-based study of meningitis in $<5$-year-olds conducted between 2005 and 2006, $3.6 \%$ (3/83 bacteriologically confirmed cases) were due to $N$. meningitidis [85]. Notably, a causal aetiology could not be identified in $80 \%$ of specimens. The authors noted high rates of prior antibiotic use, as well as evidence that only $50 \%$ of children with meningitis might reach hospital in Pakistan. Serogroup data were not available.

\section{Vietnam}

A serogroup $\mathrm{C}$ epidemic occurred in the southern provinces of Vietnam between 1977 and 1979 [29, 75]. The overall incidence rate of meningococcal disease during the epidemic rose from $<5 / 100000$ in the preceding years to $>20 / 100000$. The mortality rate was between $27 \cdot 4 \%$ and $34 \cdot 7 \%$ [29]. Seventy percent of cases occurred in children aged between 3 and 15 years.

Four prospective studies of meningitis have been conducted since the 1977 epidemic covering the years 1993-2005 [47, 86-88]. Meningococcal disease accounted for $0.5 \%$ of positive blood cultures and around $4-8 \cdot 5 \%$ of bacterial meningitis cases where an aetiology was identified. Between 2000 and 2002 the estimated incidence of meningococcal meningitis in Hanoi, Vietnam, was 21.8/100 000 (95\% CI 5.0-94.4) in children aged 7-11 months and 2.6/100000 in children aged $<5$ years $(95 \%$ CI $0 \cdot 8-8 \cdot 5)$ [47]. Serogroup data were not available.

\section{Laos, Sri Lanka and Cambodia}

We found no information on meningococcal disease from these countries.

\section{BURDEN OF DISEASE IN NON-GAVI ELIGIBLE COUNTRIES IN ASIA}

Although generally more information was available for non-GAVI eligible countries, the published data were still incomplete. Incidence rates have been calculated where possible. However, systematic presentations of epidemiological estimates were not feasible.

\section{China}

\section{Epidemic meningococcal disease}

Meningococcal disease is endemic in China, and regional or nationwide epidemics have occurred periodically over the last century. Much of the published literature describes these epidemic cycles. In the past epidemics occurred every $8-10$ years, lasting 3-5 years [89] with the majority of cases occurring between October and June [90]. During the worst epidemics, incidence rates of up to 2000/100 000 were recorded in affected unvaccinated communes [91]. In a review of seasonal variation of meningococcal meningitis incidence rates in Hunan Province, it was noted that between 1959 and 1990 there were 16 years where the incidence was $<10 / 100000,14$ years where the overall disease incidence was between 10 and 99.99/100 000, and 2 years where the incidence was $>100 / 100000$ [90]. During the observation period a total of 38148 cases were recorded. The last epidemic in 1984 was largely attenuated due to widespread use of meningococcal polysaccharide serogroup A vaccine in adolescents and children [92].

Locally produced meningococcal polysaccharide serogroup A vaccines have been available in China since the 1950s [93]. Their widespread use since the 1970s has been associated with reductions in the incidence of meningococcal disease, particularly in older children, as well as loss of epidemic cyclic activity [89, 90, 93-95]. Prior to vaccination in Zhengzhou, children aged between 4 and 15 years represented $68.22 \%$ of all meningococcal cases, and routine vaccination of children aged < 15 years began in 1984 and 1985 [94]. Estimates of efficacy at 1 year were more than $94 \%$ after vaccination in this population [95]. In 1984 in Zhengzhou, meningococcal disease incidence was $36 \cdot 35 / 100000$. In 1985 the incidence was $10 \cdot 08 /$ 100000 , decreasing to $0 \cdot 67 / 100000$ by 1991 [94].

\section{Endemic meningococcal disease}

In a survey of bacterial meningitis in children aged $\leqslant 5$ years in Nanning City (Yining County), Guangxi 
Province between 2000 and 2002, no cases of $N$. meningitidis meningitis were observed in 303 clinically confirmed cases of bacterial meningitis out of a local population of over 141000 children [32]. However, a causative organism was identified in only $14 \%$ of cases [32]. The regional incidence of $N$. meningitidis disease was $0 \cdot 25 / 100000$ at the time of the study, attributed to widespread routine use of serogroup A polysaccharide vaccination. In 2005, the incidence of meningococcal disease in China was reported to be $0 \cdot 18-0 \cdot 2 / 100000$ [31] (Table 2).

\section{Evidence for changing meningococcal serogroup distribution over time}

Historically, meningococcus serogroup A has been largely responsible for sporadic and epidemic disease in China. Since the 1980s, the proportion of cases caused by serogroups B and C has increased [18, 89, 94]. Between 1990 and 1992, 60.9\% of 23 meningococcal meningitis cases in children aged $\leqslant 15$ years were due to serogroup B and $39 \cdot 1 \%$ to serogroup A [96].

The first recorded serogroup C outbreak in China was in a village in Guangxi Province during 2002 in which 3/15 cases died (CFR 20\%) [89]. Between 2003 and 2007, serogroup C outbreaks were reported in Anhui Province [30, 97]. Using data from the Hefei (capital city of Anhui Province) Center for Disease Control and Prevention (CDC), the incidence of meningococcal disease in the region was $2 \cdot 09 / 100000$, with a greater proportion of cases $(60.9 \%)$ occurring in urban regions [30]. In total, 386 cases were reported in the region of Hefei between 2003 and 2007. Of 135 laboratory-confirmed cases, all were serogroup C. The age-specific incidences were $6 \cdot 57 / 100000$ in the $12-17$ years group ( $1 \cdot 4 \%$ of all cases), $5 \cdot 55 / 100000$ in those aged $<6$ years $(18.4 \%$ of all cases) and $4 \cdot 71 / 100000$ in the $6-11$ years group $(18.4 \%$ of all cases). The CFR was $7 \cdot 3 \%$ with the highest CFR in the $0-5$ years age group (16.9\%). Implementation of a serogroup $\mathrm{A}$ and $\mathrm{C}$ polysaccharide vaccination programme was not successful [30]. Carriage and serogrouping studies suggest that serogroup $\mathrm{C}$ has spread through many provinces in China $[31,98]$. The first case of serogroup X invasive disease was reported in Beijing in 2007 [99].

\section{Hong Kong}

Epidemic meningococcal disease was reported in Hong Kong as early as 1918 [19]. No recent epidemics have occurred. In four hospital-based surveillance studies conducted between 1984 and 2001, only five cases of meningococcal meningitis were reported, all of which occurred in the Vietnamese minority population [33, 100-102]. All affected children were aged $<5$ years. All cases were due to serogroup B and one child died [33]. The incidence rate in the $<5$-year-old Vietnamese migrant population in Hong Kong was estimated to be $13 \cdot 0 / 100000$ (95\% CI 4-2-30·3). Government data cited in Sung et al. [33] and French et al. [102] give a meningococcal disease incidence rate in the overall population of $0 \cdot 02-0 \cdot 24 / 100000$ during the same period. Medical practitioners are required to notify the Hong Kong Centre for Health Protection of all suspected and confirmed cases of invasive meningococcal disease [103]. Notifications between 2005 and 2009 numbered between 0 and 6 [103]. No recent serogroup data are available in the literature; however, a case of serogroup $\mathrm{C}$ disease has been reported [104].

\section{Japan}

\section{Historical meningococcal disease burden in Japan}

Bacteriologically confirmed meningococcal disease must be reported to the national register of notifiable diseases in Japan. Records available since before 1920 show between 300 and 1500 meningococcal cases per year between 1920 and the early 1960s, with a peak in 1945 and around 1947 with about 4500 cases and 3500 cases, respectively [34, 105]. After 1970 the number of reported cases fell to $<100$, with fewer than 30 cases per year reported since 1980 [34, 106, 107]. There is little seasonal variation in case numbers or mortality [34].

\section{Meningococcal disease in retrospective hospital surveys}

Nationwide and local retrospective surveys of bacterial meningitis have been performed regularly via questionnaires sent to medical institutions [105, 107-120]. According to these surveys, the proportion of bacterial meningitis cases due to $N$. meningitidis since the 1990s has remained below $2 \%$. Since 2000, the proportion has been less than $1 \%$. Low rates of meningococcal disease have also been observed in hospital-based studies [121]. Under-reporting has been suggested due to problems associated with handling and laboratory detection of $N$. meningitidis and use of antibiotics prior to culture [105, 107, 120]. However, in a study of $168 \mathrm{CSF}$ samples obtained from patients of all ages throughout Japan from 2005 
to 2007 that were evaluated using PCR, no N. meningitidis was identified (0/121 positive samples) [122]. It has been estimated that fewer than 30 cases of meningococcal disease occur per year in Japan [123] (Table 2), with the majority of cases occurring in children aged $\leqslant 5$ years [34].

A large-scale surveillance study of invasive meningococcal disease conducted by the Ministry of Health is currently ongoing [124]. However, underestimation of the true disease burden is still considered a possibility, since only culture-proven meningococcal cases (less likely to be successful when antibiotics have been administered) are reported to the health authorities [124].

\section{Meningococcal serogroup distribution}

A retrospective survey examined 182 Japanese isolates collected over 30 years between 1974 and 2004 [125] using multi-locus sequence typing (MLST). Of these samples, $49 \cdot 2 \%$ were from patients, $47 \%$ were from nasopharyngeal samples collected from healthy individuals and $4 \%$ were of unknown source. Of the 182 samples, $57 \%$ (103) were serogroup B, $21 \%$ (39) were serogroup Y, $1 \%$ (1) were W-135 and $21 \%$ (39) were non-groupable. This is in line with official data concluding that although serogroup data is sparse, serogroup B followed by serogroup Y make up the majority of meningococcal disease cases in Japan [34]. Three serogroup A cases have been reported in Japan since 1999. These strains were identical to Chinese strains and all three individuals had either travelled to China or had relatives that had travelled there prior to illness [34]. Only one case of serogroup C disease has been reported from Tokyo (2003) [34]. The apparently very low disease incidence is supported by carriage data suggesting very low population carriage prevalence $(0.4 \%$ prevalence between 2000 and 2002) [126].

\section{Korea}

Five publications were identified. In a review of 140 culture-positive bacterial meningitis cases from 13 hospitals in and around Seoul between 1986 and 1995, $N$. meningitidis was the third most common cause of bacterial meningitis (nine cases, 6.4\%) in children aged $<15$ years [127], with the highest proportion of cases in children aged $>5$ years $[127,128]$. In a later, prospective population-based surveillance of Hib disease in Korea between 1999 and 2001, no N. meningitidis was isolated in 2176 children evaluated for possible meningitis [129]. However, a causative organism was only identified in $4 \%$ of abnormal CSF samples in this study for reasons that are not clear, although early use of antibiotic therapy may have contributed.

In Korean army recruits, the incidence of meningococcal disease was $2 \cdot 2 / 100000(95 \%$ CI $1 \cdot 3-3 \cdot 8)$ in 2000-2001: 1/12 cases was identified as serogroup $A$ and three cases were serogroup C [39].

A laboratory-based study of $N$. meningitidis serogroups in Korea, citing Korean Ministry of Health data, stated that between 1990 and 2001, between 2 and 13 cases of meningococcal disease occurred annually [36]. A substantial increase in disease cases occurred in 2002 (27 cases) and 2003 (38 cases) [36]. Of nine clinical isolates from across Korea during these 2 years, seven were serogroup Y, with one each being serogroups B and 29E, suggesting locally evolving meningococcal epidemiology. Since 2003, the number of $N$. meningitidis cases notified to the Korean CDC was eight in 2004, seven in 2005, 11 in 2006, four in 2007 and one in 2008 [35] (Table 2).

\section{Malaysia}

Four retrospective reviews from hospitals in various regions within Malaysia have been published [5, 13, 130, 131]. The most recent of these reviewed microbiologically confirmed meningococcal disease occurring between 1987 and 2004 in a large university hospital in Kuala Lumpur [5]. Only 17 cases (12 with data) were noted during the observation period. Seven cases occurred in the 20-35 years age group, three cases in the 10-15 years group and one case in a child aged 10 months. Mortality was $25 \%$. Of six cases where the serogroup was identified, one case was identified as serogroup B and five cases as serogroup $\mathrm{W}-135$. These data contrast with other earlier studies that suggest a significant burden of disease due to $N$. meningitidis, including infants aged $<1$ year [130]. The low detection rate in later studies may be due in part to low acceptance of lumbar puncture [13] and/or because some cases might go unrecognized.

An outbreak of suspected meningococcal disease was reported (ProMED) in trainees of the Road Transport Department (JPJ) Academy in Malacca in 2009, with 20 cases and one death [132].

\section{The Philippines}

Available information sources included five publications, a report from the WHO and annual reports 
from the Department of Health (2004-2008). Between 17 and 35 cases of meningococcal disease were reported annually to the Department of Health between 2004 and 2008, with the exception of 2005 when 115 cases were reported [38]. This increase was due to a meningococcal serogroup A outbreak that occurred in the regions of Baguio City, Mt Province and Ifuga in the Philippines in 2004 and 2005, with 98 cases ( $33 \%$ mortality) reported to the WHO up to January 2005 [27]. The incidence per population in the nonoutbreak years ranged between $0 \cdot 0$ and $0 \cdot 04 / 100000$ (Table 2) but there was marked variability between regions [38]. In non-outbreak years between $34 \%$ and $50 \%$ of cases were reported in children aged $<5$ years. In 2005 most cases $(88 / 115)$ were reported in the 5-49 years age group [38].

An outbreak of meningococcal disease, probably due to serogroup A, of 10 cases (incidence 65/100 000 population) was reported in 1989 in San Jose, Sipalay, Negros Occidental [133]. All but one case had meningococcaemia and mortality was $50 \%$. Seven of 10 cases occurred in individuals aged $\leqslant 19$ years [133].

Three prospective hospital-based studies in children, carried out between 1991 and 2000, failed to identify $N$. meningitidis in Filipino children with serious infections including meningitis [134-136]. Notably, in two of these studies, culture was successful in only around $8 \%$ of cases $[134,136]$. Earlier retrospective hospitalbased studies conducted during the 1980s detected $N$. meningitidis in up to $16 \cdot 7 \%$ of children aged $<15$ years with meningitis, with most cases occurring in children aged $<5$ years [137, 138].

\section{Singapore}

The number of invasive meningococcal disease cases reported to the Singapore Ministry of Health over the last 5 years was five in 2009, six in 2008, five in 2007, ten in 2006 and five in 2005 [40] (Table 2). Estimations of the proportion of meningitis cases caused by $N$. meningitidis have been made in adults and children in five retrospective hospital-based studies carried out between 1975 and 2000 [139-144]. In studies with available data, the proportion of culture-negative meningitis cases was high (between $30 \%$ and $55 \%$ ) and in one study [139], $55 \%$ of subjects had received antibiotics prior to admission to hospital. In adults, $N$. meningitidis was present in up to $20 \%$ of community-acquired cases of bacterial meningitis [139]. In children, $N$. meningitidis accounted for between $0 \%$ and $12.5 \%$ of cases, with decreasing frequency over time from the 1970s to the 1990s.

Little data about prevailing serogroups are available. Cases of meningococcal disease identified between 1975 and 1979 were a result of serogroups X, Y or Z [144]. Between 1981 and 2000, 66 cases of meningococcal disease were described [140]. The age of the patients ranged from 3 weeks to 81 years; $28 / 58$ serogroupable strains were serogroup B (53\%), $10(18 \%)$ serogroup $\mathrm{C}$ and nine $(16 \%)$ serogroup W-135. Mortality was $22 \cdot 7 \%$.

Disease due to serogroup W-135 was not detected in Singapore prior to 2000 but has since been observed, mainly affecting Hajj pilgrims and their contacts [41]. Twelve cases of serogroup W-135 meningitis were documented in Singapore between 2000 and 2001 (age range 1-75 years), eight of whom were Hajj pilgrims or their contacts [41, 145, 146]. There was one death and the attack rate for serogroup $\mathrm{W}-135$ disease in Singaporee Hajj pilgrims was estimated at 25/100 000 .

\section{Taiwan}

N. meningitis as a cause of all bacterial meningitis

Prospective [147, 148] and retrospective [149-156] hospital-based studies conducted between 1981 and 2005 show $N$. meningitidis to be a relatively uncommon cause of bacterial meningitis in all age groups. $N$. meningitidis was responsible for between $0 \%$ and $2.5 \%$ of meningitis cases in adults (with the exception of one study showing $6 \%[155]$ ), and $3 \cdot 5-4 \cdot 95 \%$ of cases in children aged $<15$ years. Nevertheless, in one prospective study, $N$. meningitidis was the third most common cause of meningitis in children aged $>2$ months [147].

\section{$\mathrm{N}$. meningitidis occurrence and changing incidence over time}

Epidemics of serogroup A meningococcal disease occurred in Taiwan between 1919 and 1926, and 1933 and 1946 [28] with about 300 cases reported in each outbreak year. Meningococcal disease has been notified to the Taiwan CDC since the 1950s [157]. Between 1950 and 2001, 659 meningococcal cases were reported with peaks in 1953 (incidence rate $0.94 /$ $100000)$ and $1959(0 \cdot 52 / 100000)$, dropping to very low levels over the ensuing decades [157]. In 1991 the incidence of meningococcal disease was estimated by the CDC to be $0 \cdot 22 / 100000$, with the highest rate in 
20 - to 24 -year-olds $(0 \cdot 38-0 \cdot 71 / 100000$ according to region [158]) (Table 2). Prior to 2001, between 17 and 34 meningococcal disease cases were reported each year [43] and in 2000 the incidence rate in Taiwan was estimated to be $0 \cdot 07 / 100000$ [41]. The mean age was $19 \cdot 4$ years, $33 \cdot 6 \%$ were aged between 11 and 30 years and $31.3 \%$ were $<1$ year old.

In 2001 and 2002, changes in the epidemiology of meningococcal disease in Taiwan were observed in terms of incidence, serogroup distribution and possibly the age distribution of cases. The overall incidence more than doubled in $2001(0 \cdot 19 / 100000)$ [41, 43] with an overall mortality of $25 \cdot 6 \%$ [157]. Cases were geographically dispersed and none had travelled to the Hajj or had contact with Hajj pilgrims [157]. The age distribution of 115 cases collected between 2001 and 2003 was: $<1$ year, 27 cases $(23.5 \%) ; 1-9$ years, 16 cases $(13.9 \%)$; $10-19$ years, 16 cases $(13.9 \%) ; 20-54$ years, 37 cases $(32 \cdot 2 \%) ; \geqslant 55$ years, 19 cases $(16 \cdot 5 \%)$ [41].

In recent years the incidence of meningococcal disease cases appears to have gone back to levels observed prior to 2001-2002. The number of meningococcal disease cases reported to the Taiwan CDC from 2006 was 13 in 2006, 20 in 2007, 19 in 2008, two in 2009 and one case to date in 2010 [159].

\section{Evidence for changing meningococcal serogroup distribution over time}

Serogroups B and W-135 predominated in Taiwan prior to $2001[43,160,161]$. Serogroup B was responsible for $48 \cdot 8 \%$ of meningococcal cases between 1995 and 1999 [160] and for 84.6\% (11/13) in 1999 [43]. Concurrent with an increase in disease incidence in 2001 and 2002 has been an apparent change in the serogroup distribution of cases. Of 115 confirmed cases collected between 2001 and 2003, 55 (47.8\%) were serogroup B, 30 (26.1\%) were serogroup W-135, $17(14.8 \%)$ were serogroup Y, six $(5 \cdot 2 \%)$ were nongroupable, four $(3.5 \%)$ were serogroup $\mathrm{C}$ and three $(2 \cdot 6 \%)$ were serogroup A [41]. Serogroup Y appeared for the first time in 2001, and cases of disease due to serogroups $\mathrm{A}$ and $\mathrm{C}$ also started to emerge at this time $[43,157]$. These serogroups A, C and Y meningococcal strains were identified as worldwide epidemic clones [43].

\section{Thailand}

Between 1981 and 1990 the incidence of meningococcal disease was cited as $0 \cdot 03-0 \cdot 2 / 100000$ population by government sources (Annual Epidemiology Surveillance Report 1990 cited in [46]). In 2007 and 2008 the incidence rates were unchanged, with 30 and 15 meningococcal disease cases reported to the Bureau of Epidemiology, respectively (incidence of 0.02-0.05/ 100000 population) [44]. The highest incidence was observed in children aged $<5$ years $(0 \cdot 1-0 \cdot 3 /$ 100000 ), and case fatality was $33 \cdot 3 \%$ in 2007 and $13.33 \%$ in 2008. Most notifications came from regions in the south. No seasonality was observed and serogroup B was the only serogroup identified [44].

Retrospective hospital-based studies have also detected few meningococcal disease cases $[4,11,46$, 162-165]. Of 36 culture-positive meningococcal cases observed in 13 government hospitals throughout Thailand between 1994 and 1999, 22/36 (61·1\%) cases occurred in children aged $<15$ years, with a peak in children aged $<5$ years. Of 16 serogrouped isolates, serogroup B was most frequently represented (9/16); serogroup A was identified in two cases and serogroups C and W-135 in one case each. A meningococcal carriage study between 1983 and 1984 showed that $14 \cdot 23 \%$ of children aged between 5 and 15 years were nasopharyngeal carriers of $N$. meningitidis. The authors postulated that the apparently very low incidence of meningococcal disease in Thailand was spurious, due to over-the-counter availability of antibiotics and technical problems in laboratories such as lack of after-hours facilities [11]. Corroborating this hypothesis, a well conducted prospective populationbased survey of bacterial meningitis in two northern provinces (Lampang, Phitsanulok) of Thailand between 2000 and 2001 estimated a rate of meningococcal meningitis that was tenfold higher in children aged $<5$ years $(1 \cdot 8 / 100000)$ [45]. In this study, health workers and laboratory staff were trained and laboratory methods optimized. Lumbar puncture was performed in $76.1 \%$ of 598 enrolled children and $94.3 \%$ of samples were tested by PCR, including testing for $N$. meningitidis.

\section{SUMMARY}

Data describing the epidemiology of meningococcal disease in Asia are incomplete. Yet it is apparent that the burden of disease due to $N$. meningitidis, and prevailing serogroups, are highly heterogenous across Asia. This is not surprising given variations across the region in climate (from temperate to tropical to dry desert), socio-demography (with overcrowding in some regions and variable access to health care 
facilities), economic settings (reflecting the spectrum of developed and developing countries), and religious practices (including a substantial Muslim population in some countries that attend Hajj, which is associated with meningococcal disease outbreaks). All of these factors can influence meningococcal disease epidemiology, as well as the ability to detect and treat cases and implement surveillance.

Widespread devastating meningococcal serogroup A epidemics have occurred in China, Hong Kong, India, Mongolia, Nepal, Pakistan, the Philippines and Taiwan over the last century. Since 1980, six serogroup A epidemics have been reported in Asian countries, including India (two epidemics, most recently in 2005), Mongolia, Nepal, Pakistan and the Philippines (also in 2005). Almost 10000 cases of epidemic meningococcal disease have been reported during these epidemics. Reported epidemic mortality ranged between $7 \%$ and $33 \%$. More recently, other serogroups have been responsible for local outbreaks in China (serogroup C [30]), Singapore (serogroup W-135 [41]) and Taiwan (serogroup Y [43]). Although some countries (Thailand, Malaysia, Indonesia) require vaccination of Hajj pilgrims against meningococcal disease with tetravalent ACWY polysaccharide vaccines, we found evidence of routine mass meningococcal vaccination only in China [166]. Polysaccharide serogroup A vaccines were used for outbreak/ epidemic control during the late 1970s and 1980s. Since the 1980s, vaccination of children with two doses of serogroup A vaccine between 6 and 18 months of age, and vaccination with serogroup $A$ and $C$ vaccine at 3 and 6 years of age is recommended [165]. Coverage is reported to be very high [167]. In Korea, the Korean Paediatric Society recommends meningococcal vaccination for high-risk groups (asplenia, complement deficiency, travellers to endemic areas) [168], although no meningococcal polysaccharide or conjugate vaccine is currently available. No meningococcal conjugate vaccines are currently routinely recommended in any of the other countries we studied in this review.

Endemic meningococcal disease epidemiology is even less well described across Asia. In individual studies $N$. meningitidis was one of the three most common causes of meningitis in children in India [169], Korea [127], Pakistan [82] and Taiwan [147] and in adults in India [170] and Pakistan [10]. Ready access to antibiotics and laboratory-related technical issues have clearly influenced $N$. meningitidis detection rates in Asia. Widespread availability and use of more precise tools such as PCR, as well as the establishment of ongoing surveillance systems, are needed to improve disease ascertainment in many countries.

In countries with available historical time series data (India, China, Japan, Korea, Singapore, Taiwan), the contribution of $N$. meningitidis to childhood and adult meningitis has apparently fallen to very low levels per 100000 population over the last century (Table 2). In China this has been largely attributed to widely implemented polysaccharide vaccine immunisation programmes. In other countries the reason for the reduction in cases is less clear, but may be linked to improving socio-economic conditions, although similar variability in Hib and pneumococcal disease across Asia has been observed [171, 172]. Understanding the reasons behind this apparently very low disease incidence in these countries remains an epidemiological challenge and is an important topic of future epidemiological research. These apparent reductions are in marked contrast to the situation in developing GAVI-eligible countries where the available data suggest an important, ongoing meningococcal disease burden affecting children and adults. The disease burden appears both epidemic and endemic, but remains poorly described.

Available estimates for meningococcal disease in developed countries in the 21 st century are no more than $2 \cdot 6 / 100000$ population in any country, although higher rates are observed in some specific groups, such as the Vietnamese immigrant community in Hong Kong and Hajj pilgrims in Singapore (Table 2). Notably, disease incidence estimates were not available for 12 of the 20 countries we studied, including 9/11 GAVI-eligible countries. Based on the limited available evidence, population disease incidence rates in GAVI-eligible countries are expected to be higher than those in industrialized countries within Asia. In 1997 the WHO estimated that 160000 cases of meningitis occurred in South East Asia, of which 55000 were due to non-epidemic meningococcal disease [173].

The available serogroup data indicate that all of the five major disease-causing meningococcal serogroups are present in Asia, albeit with wide variability in their distribution across the region. Serogroup A dominates in Bangladesh, and in China and India during epidemic years, while serogroups $\mathrm{B}$ and $\mathrm{C}$ are present in sporadic cases, with evidence of more serogroup B and $\mathrm{C}$ disease in China since the 1980s [18, 89, 94]. Serogroup B is most commonly implicated as a cause of sporadic disease in Japan, Singapore, Thailand and 
Taiwan, and is present in Malaysia, Mongolia and Indonesia. Important contributions to disease are made by serogroup $\mathrm{Y}$ in Japan and Taiwan, serogroup C in Singapore and serogroup W-135 in Singapore and Taiwan.

We found evidence of evolving meningococcal disease epidemiology in Mongolia, Nepal, China, India, Korea, Japan, Singapore and Taiwan, with strain importation clearly implicated in some countries. Epidemics of serogroup A disease were first described relatively recently in Mongolia [77] and Nepal [61] in the 1970s and 1980s. In China and India where serogroup A has historically dominated, there is some evidence that serogroup B meningitis has subsequently emerged [67, 96]. Additionally, serogroup $\mathrm{C}$ has become established in some regions of China since 2002 [30]. In Japan, serogroup A was first identified in 1999 and was probably imported from China, while the first serogroup $\mathrm{C}$ case was identified in 2003 [34]. In Taiwan, serogroups A, C and Y have been observed since 2000 [43]. In Singapore, serogroup W-135 appeared for the first time in 2000 in Hajj pilgrims and their contacts [41]. The large Asian Muslim population points to an ongoing risk of future Hajj-related outbreaks. Circulation of multiple serogroups, as well as evidence of changing serogroup distribution, argue for use of meningococcal vaccines giving broad coverage, such as tetravalent ACWY conjugates, in many countries in Asia. Furthermore, broad coverage by tetravalent vaccines may be the vaccination strategy of choice in those countries as yet without routine surveillance and precise serogroup information.

The absence of high-quality disease surveillance systems among many countries in Asia is likely to contribute to delays in making informed decisions about the potential benefits of introducing vaccination programmes. This has been the case for both Hib and S. pneumoniae, where implementation of universal mass vaccination has been slow in Asian countries due to lack of epidemiological data [172, 174]. This review has highlighted problems that are manifested across most of the region for detecting cases of meningococcal disease. As observed for studies describing the burden of Hib and pneumococcal disease in Asia, under-detection is a major problem due to high levels of prior antibiotic use and suboptimal procedures associated with sample handling and laboratory testing in some countries [172, 174]. Access to more sensitive molecular technologies such as PCR is needed, and country-specific issues such as fears surrounding lumbar puncture, and lack of access to hospital care for many sick children, will also need to be overcome in order to more accurately assess the true disease burden. A further problem is that the ability to apply standardized meningococcal case definitions such as those advocated by WHO [175] will differ regionally, with clinical diagnoses most likely in rural areas and case confirmation only possible in areas with well-equipped laboratories $[3,175]$.

There is currently only limited information available to assess the burden of meningococcal disease in much of developing Asia, and it is likely to be underrecognised. Therefore, there is a need for introducing and improving surveillance capacity across the region to more accurately assess the disease burden and determine serogroup distribution. Meningococcal serogroup A outbreaks represent an ongoing threat, and importation of previously unseen serogroups poses a continuing potential epidemic risk in Asia. Mulitvalent meningococcal conjugate vaccines targeting the major disease-causing serogroups (e.g. A, C, W-135 and $\mathrm{Y}$ conjugate vaccines that are now available), particularly if licensed for use in younger children, may offer opportunities for disease control in the region. There may also be a role for a serogroup $\mathrm{B}$ vaccine in the region once one becomes available that can provide broad protection against serogroup B disease.

\section{NOTE}

Supplementary material accompanies this paper on the Journal's website (http://journals.cambridge.org/ hyg).

\section{ACKNOWLEDGEMENTS}

The authors thank Dr Motomi Osato (Japan), Dr Li Yuqing, Dr. Zhang Weidong, Dr Yang Yong, and Dr Chen Chuanfei (China) for assistance in translation. The authors also thank Dr Tatjana Mijatovic and Dr Stephanie Harbers for editorial assistance.

$\mathrm{T}$. $\mathrm{Ng}$ is currently affiliated with Novartis Asia Pacific Pharmaceuticals Pte Ltd; M. Soriano-Gabarro is currently affiliated with BayerSchering Pharma.

\section{DECLARATION OF INTEREST}

A.V. and J.C. are employees of GlaxoSmithKline Biologicals, a vaccine company that manufactures 
meningococcal vaccines. T.N., M.S-G. and J.M.W. are previous employees of GlaxoSmithKline Biologicals. J.M.W. received payment for her contribution to the writing of this manuscript.

\section{REFERENCES}

1. Rosenstein NE, et al. Meningococcal disease. New England Journal of Medicine 2001; 344: 1378-1388.

2. United Nations Population Information Network (http:// www.un.org/popin/data.html). Accessed 24 December 2009.

3. Harrison LH, Trotter CL, Ramsay ME. Global epidemiology of meningococcal disease. Vaccine 2009; 27 : B51-B63.

4. Pancharoen C, et al. Epidemiology of invasive meningococcal disease in 13 government hospitals in Thailand, 1994-1999. Southeast Asian Journal of Tropical Medicine and Public Health 2000; 31: 708-711.

5. Raja NS, et al. Invasive meningococcal disease in the University of Malaya Medical Centre, Kuala Lumpur, Malaysia. Journal of Postgraduate Medicine 2006; 52: 23-29.

6. Yang YH, et al. Abuse of antibiotics in China and its potential interference in determining the etiology of pediatric bacterial diseases. Pediatric Infectious Disease Journal 1993; 12: 986-988.

7. Ahlawat S, et al. Meningococcal meningitis outbreak control strategies. Journal of Communicable Diseases $2000 ; 32$ : 264-274.

8. Chinchankar $\mathbf{N}$, et al. Diagnosis and outcome of acute bacterial meningitis in early childhood. Indian Pediatrics 2002; 39: 914-921.

9. Lupisan SP, et al. Invasive bacterial infections of children in a rural province in the central Philippines. American Journal of Tropical Medicine and Hygiene 2000; 62: 341-346.

10. Shaikh S, Shaikh RB, Faiz MS. Seasonal paradox in acute meningitis at Nawabshah. Journal of the College of Physicians and Surgeons Pakistan 2003; 13: 207-209.

11. Danchaivijitr S, et al. Meningococcal carriers in school children. Journal of the Medical Association of Thailand 1988; 71: 537-540.

12. Granoff DM, Feavers IM, Borrow R. Meningococcal vaccines. In: Plotkin SA, Orenstein WA, eds. Vaccines, 4th edn. Philadelphia: Saunders, 2004, pp. 959-987.

13. Hussain IH, et al. Haemophilus influenzae meningitis in Malaysia. Pediatric Infectious Disease Journal 1998; 17: S189-S190.

14. Zaidi AK, et al. Surveillance of pneumococcal meningitis among children in Sindh, southern Pakistan. Clinical Infectious Diseases 2009; 48: S129-S135.

15. United Nations: Population Division. 2008 revision population database: world population prospects. Medium variant selected (http://esa.un.org/unpp/ index.asp?panel=2). Accessed 17 August 2010.
16. GAVI alliance Support. Who is eligible? (http://www. gavialliance.org/support/who/eligible/index.php). Accessed 12 December 2007.

17. Hossain MA, et al. Increasing isolations of Neisseria meningitidis serogroup A from blood and cerebrospinal fluid in Dhaka, Bangladesh, 1999-2006. American Journal of Tropical Medicine and Hygiene 2009; 80: 615-618.

18. Hu X. Surveillance of epidemiological features for epidemic cerebrospinal meningitis in China during 1980s. Zhonghua Liu Xing Bing Xue Za Zhi 1990; 11: 321-324.

19. Hu Z. Epidemiology of meningococcal disease in China. In Vedros NA, ed. Evolution of Meningococcal Disease, Vol. II. Boca Raton, FL: CRC Press, Inc., 1987, pp. 19-32.

20. Nair D, et al. Outbreak of meningococcal disease in and around New Delhi, India, 2005-2006: a report from a tertiary care hospital. Epidemiology and Infection 2009; 137: 570-576.

21. World Health Organization. Country office for India. Core Programme Clusters. Outbreaks Meningococcal meningitis 2005 (http://www.whoindia.org/EN/ Section3/Section262/Section350_839.htm). Accessed 24 December 2009.

22. World Health Organization. Regional Office for SouthEast Asia. Communicable Diseases Department. Past outbreaks of meningococcal meningitis in SEA Region - a brief overview (http://www.searo.who.int/ en/section10/section1973_9755.htm). Accessed 17 March 2010 .

23. World Health Organization. Meningococcal disease. Weekly Epidemiological Record 1995; 70: 281-282.

24. Skalova R. Epidemiology of meningococcal meningitis in Sahel and Mongolia. Infection 1984; 12: S35-S43.

25. Cochi SL, et al. Control of epidemic group A meningococcal meningitis in Nepal. International Journal of Epidemiology 1987; 16: 91-97.

26. Dure-Samin A, Mubina A, Azra Y. An epidemic of meningococcal disease in Karachi (Pakistan): a study of children. Acta Paediatrica Japan 1991; 33: 352-366.

27. World Health Organization. Epidemic and pandemic alert and response (EPR). Meningococcal disease in the Philippines-update 2 2005. (http://www.who. int/csr/don/2005_01_28a/en/index.html). Accessed 30 December 2009.

28. Center for Disease Control Department of Health Taiwan. An epidemiological investigation of a suspected meningococcal meningitis outbreak at a military camp. Epidemiology Bulletin 2002; 18: 1-16.

29. Oberti J, et al. An epidemic of meningococcal infection in Vietnam (southern provinces). Bulletin of the World Health Organization 1981; 59: 585-590.

30. Ni JD, et al. Recent epidemiological changes in meningococcal disease may be due to the displacement of serogroup A by serogroup C in Hefei City, China. Postgraduate Medical Journal 2008; 84: 87-92.

31. Zhang X, et al. Molecular characterization of serogroup C Neisseria meningitidis isolated in China. Journal of Medical Microbiology 2007; 56: 1224-1229. 
32. Dong BQ, et al. Epidemiologic surveillance for bacterial meningitis in 140000 children under 5 years of age in Nanning district, Guangxi province. Zhonghua Liu Xing Bing Xue Za Zhi 2004; 25: 391-395.

33. Sung RY, et al. Meningitis in Hong Kong children, with special reference to the infrequency of Haemophilus and meningococcal infection. Journal of Paediatrics and Child Health 1997; 33: 296-299.

34. Infectious Agents Surveillance Report. Meningococcal meningitis, 1999-2004, Japan. Infectious Agents Surveillance Report 2005; 26: 33-34.

35. Korea Centers for Disease Control and Prevention. Public Health Weekly Report, week 52, 2009 (http:// www.cdc.go.kr/eng/english/kcdc_01.htm). Accessed 17 March 2010.

36. Bae SM, Kang YH. Serological and genetic characterization of meningococcal isolates in Korea. Japanese Journal of Infectious Disease 2008; 61: 434-437.

37. Mendsaikhan $\mathbf{J}$, et al. Childhood bacterial meningitis in Ulaanbaatar, Mongolia, 2002-2004. Clinical Infectious Diseases 2009; 48: S141-S146.

38. Field Health Service Information System. Division of Public Health Surveillance and Informatics. National Epidemiology Center. Department of Health Manila, Philippines. Annual reports 2004, 2005, 2006, 2007 and 2008.

39. Lee SO, et al. Meningococcal disease in the republic of Korea army: incidence and serogroups determined by PCR. Journal of Korean Medical Science 2003; 18: 163-166.

40. Singapore Ministry of Health. Infectious Disease Bulletin (http://www.moh.gov.sg/mohcorp/statistics.aspx? $\mathrm{id}=90)$. Accessed 17 March 2010.

41. Wilder-Smith A, et al. Hajj-associated outbreak strain of Neisseria meningitidis serogroup W135: estimates of the attack rate in a defined population and the risk of invasive disease developing in carriers. Clinical Infectious Diseases 2003; 36: 679-683.

42. Wang JL, et al. Clinical features and outcome of sporadic serogroup W135 disease Taiwan. BMC Infectious Diseases 2006; 6: 7.

43. Chiou CS, et al. Molecular epidemiology and emergence of worldwide epidemic clones of Neisseria meningitidis in Taiwan. BMC Infectious Diseases 2006; 6: 25 .

44. Thai Department of Disease Control, Ministry of Public Health. Surveillance Reports 2007 and 2008 (http:// epid.moph.go.th/). Accessed 17 March 2010.

45. Rerks-Ngarm S, et al. Prospective population-based incidence of Haemophilus influenzae type b meningitis in Thailand. Vaccine 2004; 22: 975-983.

46. Chotpitayasunondh T. Bacterial meningitis in children: etiology and clinical features, an 11-year review of 618 cases. Southeast Asian Journal of Tropical Medicine and Public Health 1994; 25: 107-115.

47. Anh DD, et al. Haemophilus influenzae type B meningitis among children in Hanoi, Vietnam: epidemiologic patterns and estimates of $H$. influenzae type B disease burden. American Journal of Tropical Medicine and Hygiene 2006; 74: 509-515.
48. d-maps.com. Map of Asia (http://d-maps.com/pays. php?lib=asia_maps\&num_pay=65\&lang=en). Accessed 19 April 2010.

49. Saha SK, et al. The increasing burden of disease in Bangladeshi children due to Haemophilus influenzae type b meningitis. Annals of Tropical Paediatrics 1997; 17: 5-8.

50. Khan WA, et al. Bacterial meningitis in a diarrhoeal disease treatment centre in Bangladesh, and susceptibility of the pathogens to antimicrobials. Acta Paediatrica 1995; 84: 693-694.

51. Mitra AK, Albert MJ, Alam AN. Bacteraemia and meningitis among hospital patients with diarrhoea. Transactions of the Royal Society of Tropical Medicine and Hygiene 1993; 87: 560-563.

52. Setarunnahar, Hoq F, Chowdhury AA. Aetiological agents of meningitis in Bangladeshi children. Indian Journal of Medical Microbiology 1988; 4: 81-85.

53. ProMED mail. PRO/EDR Meningitis, meningococcal India: (Meghalaya). 17 Jan. 2009: 20090117.0206 (http://www.promedmail.org). Accessed 25 November 2010.

54. ProMED mail. Meningitis, meningococcal - India (02): (NE), Bangladesh spread 11 Feb. 2009: 20090211.0621 (http://www.promedmail.org). Accessed 25 November 2010.

55. Singhal S, et al. Ciprofloxacin-resistant Neisseria meningitidis, Delhi, India. Emerging Infectious Diseases 2007; 13: 1614-1616.

56. National Institute of Communicable Disease. Zone-wise attack rate of meningococcal disease in Delhi from 12 April-23 June 2005 (http://www.whoindia.org/ LinkFiles/Meningitis_Meningitis_attack_rate.pdf).

Accessed 24 December 2009.

57. ProMED mail. $\mathrm{PRO} / \mathrm{EDR}>$ Meningitis - India (Bihar) (02). 13 December 2000: 20001213.2173 (http://www. promedmail.org). Accessed 25 November 2010.

58. ProMED mail. PRO/EDR Meningitis, meningococcal India (03): (NE), RFI. 16 Feb. 2009: 20090216.0657 (http://www.promedmail.org). Accessed 25 November 2010.

59. ProMED mail. Meningitis, meningococcal - India (06): (ML). 06 July 2009: 20090706.2426 (http://www. promedmail.org). Accessed 25 November 2010.

60. Pulickal AS, Mathew AM, Xavier D. Patterns and outcome of acute bacterial meningitis in a South Indian tertiary level hospital. Indian Journal of Public Health 2005; 49: 254-255.

61. Cherukupally SR, Eavey R. Vaccine-preventable pediatric postmeningitic sensorineural hearing loss in southern India. Otolaryngology and Head and Neck Surgery 2004; 130: 339-343.

62. Mani R, et al. Bacteriological profile of community acquired acute bacterial meningitis: a ten-year retrospective study in a tertiary neurocare centre in South India. Indian Journal of Medical Microbiology 2007; 25: 108-114.

63. Singhi SC, et al. Evaluation of polymerase chain reaction (PCR) for diagnosing Haemophilus influenzae 
b meningitis. Annals of Tropical Paediatrics 2002; 22: 347-353.

64. Sahai S, et al. Childhood bacterial meningitis in Pondicherry, South India. Indian Journal of Pediatrics 2001; 68: 839-841.

65. Seetha KS, Murthy R, Shivananda PG. Incidence of meningitis in Manipal. Indian Journal of Public Health 1999; 43: 82-84.

66. Shameem $\mathbf{S}$, et al. Bacterial meningitis: rapid diagnosis and microbial profile: a multicentered study. Journal of Communicable Diseases 2008; 40: 111-120.

67. Suri M, et al. Group B meningococcal meningitis in India. Scandinavian Journal of Infectious Disease 1994; 26: 771-773.

68. Ayyagari A, Dubey ML, Bhandari SK. Sulphadiazine resistant strains of Neisseria meningitidis during an outbreak of meningococcal meningitis. Indian Journal of Medical Research 1987; 85: 249-252.

69. Pusponegoro HD, et al. Epidemiologic study of bacterial meningitis in Jakarta and Tangerang: preliminary report. Pediatric Infectious Disease Journal 1998; 17: S176-178.

70. Gessner BD, et al. Incidences of Vaccine-preventable Haemophilus influenzae type b pneumonia and meningitis in Indonesian children: hamlet-randomised vaccine-probe trial. Lancet 2005; 365: 43-52.

71. World Health Organization. 2000 - Meningococcal disease in Singapore, Indonesia, Iran and Morocco (http:// www.who.int/csr/don/2000_05_03/en/index.html). Accessed 17 March 2010.

72. Ruspandji T, et al. Acute purulent meningitis in infants and children. Modern Medicine of Asia 1981; 17: 35-37.

73. Lembong CM, Djamin J, Kristanti L. Evaluation on cephaloridine in the treatment of purulent meningitis in children. Paediatrica Indonesiana 1972; 12: 377-384.

74. Madjid S, Madjid A. The etiology of meningitis in children of Jakarta. Paediatrica Indonesiana 1965; 5: 743-751.

75. Manchanda V, Gupta S, Bhalla P. Meningococcal disease: history, epidemiology, pathogenesis, clinical manifestations, diagnosis, antimicrobial susceptibility and prevention. Indian Journal of Medical Microbiology 2006; 24: 7-19.

76. Jamba G, et al. Immunization during a cerebrospinal meningitis epidemic in the Mongolian People's Republic, 1974-75. Bulletin of the World Health Organization 1979; 57: 943-946.

77. World Health Organization. Regional Office for SouthEast Asia. Communicable Diseases Department. Country Health Profile - Myanmar 2004 (http://www. searo.who.int/en/section313/section1522_6852.htm). Accessed on 1 January 2007.

78. Centers for Disease Control (CDC). Epidemic meningococcal disease: recommendations for travelers to Nepal. Morbidity and Mortality Weekly Report 1985; 34: 119-20, 125.

79. Sharma PR, et al. Intravenous chloramphenicol plus penicillin versus intramuscular ceftriaxone for the treatment of pyogenic meningitis in Nepalese children. Tropical Doctor 1996; 26: 84-85.
80. Tiwari KB, et al. Acute bacterial meningitis in Nepal. Nepal Medical College Journal 2007; 9: 100-103.

81. Shah AS, et al. Invasive pneumococcal disease in Kanti Children's Hospital, Nepal, as observed by the South Asian Pneumococcal Alliance network. Clinical Infectious Diseases 2009; 48: S123-S128.

82. Qazi SA, et al. Dexamethasone and bacterial meningitis in Pakistan. Archives of Disease in Childhood 1996; 75 : 482-488.

83. Rabbani MA, et al. Spectrum of complications and mortality of bacterial meningitis: an experience from a developing country. Journal of the Pakistan Medical Association 2003; 53: 580-583.

84. Rajper GM, et al. Bacterial pyogenic meningitis and drug sensitivity: one year study at People's Medical College, Nawabshah, Pakistan. Specialist 1997; 13: 123-125.

85. Zaidi AK, et al. Surveillance of pneumococcal meningitis among children in Sindh, southern Pakistan. Clinical Infectious Diseases 2009; 48: S129-S135.

86. Tran TT, et al. The etiology of bacterial pneumonia and meningitis in Vietnam. Pediatric Infectious Disease Journal 1998; 17: S192-S194.

87. Hoa NT, et al. Community-acquired septicaemia in southern Viet Nam: the importance of multidrugresistant Salmonella typhi. Transactions of the Royal Society of Tropical Medicine and Hygiene 1998; 92: 503-508.

88. Nguyen TH, et al. Dexamethasone in Vietnamese adolescents and adults with bacterial meningitis. New England Journal of Medicine 2007; 357: 2431-2440.

89. Li J, et al. Serum antibody level of meningococcal meningitis in health people in Hubei Province in 2003. Zhonghua Liu Xing Bing Xue Za Zhi 2004; 25 : 996.

90. Wang W. A study on seasonal variation of epidemic cerebrospinal meningitis with circular distribution method. Zhonghua Liu Xing Bing Xue Za Zhi 1994; 15: 286-288.

91. Deng ZM. Epidemiologic survey of an outbreak of meningococcal meningitis associated with the social customs of the Shui Minority Nationality. Zhonghua Liu Xing Bing Xue Za Zhi 1985; 6: 211-213.

92. Hu X. Study on periodically prevalent feature for epidemic cerebrospinal meningitis in China. Zhonghua Liu Xing Bing Xue Za Zhi 1991; 12: 136-139.

93. Ma Z. Observation on the epidemiologic efficacy for 9 years on epidemic meningococcal polysaccharide vaccine of group A by district immunization method. Zhonghua Liu Xing Bing Xue Za Zhi 1991; 12: 69-71.

94. Wei JJ. Changes in epidemic features of epidemic cerebrospinal meningitis after vaccination with purified meningococcal polysaccharide vaccine group A in Zhengzhou. Zhonghua Yu Fang Yi Xue Za Zhi 1993; 27: 160-161.

95. Wei RT. Immunizing reactivity following vaccination with a purified fraction of Neisseria meningitidis and observations of effectiveness throughout 3 years. Zhonghua Liu Xing Bing Xue Za Zhi 1982; 3: 4-7. 
96. Yang Y, et al. Acute bacterial meningitis in children in Hefei, China 1990-1992. Chinese Medical Journal 1996; 109: 385-388.

97. Shao Z, et al. Identification of a new Neisseria meningitidis serogroup C clone from Anhui province, China. Lancet 2006; 367: 419-423.

98. Zhang TG, et al. The molecular characterization of serogroup C Neisseria meningitidis strains circulating in Beijing. Journal of Microbiology 2006; 44: 685-688.

99. Chen C, et al. A first meningococcal meningitis case caused by serogroup X Neisseria meningitidis strains in China. Chinese Medical Journal 2008; 121: 664-666.

100. Hui AC, et al. Bacterial meningitis in Hong Kong: 10-years' experience. Clinical Neurology and Neurosurgery 2005; 107: 366-370.

101. Cheng AF, et al. A five-year prospective study of septicaemia in hospitalized children in Hong Kong. Journal of Tropical Medicine and Hygiene 1991; 94: 295-303.

102. French GL, et al. Septicaemia in Hong Kong. Journal of Antimicrobial Chemotherapy 1990; 25: 115-125.

103. Center for Health Protection. Department of Health. The Government of the Hong Kong Special Administrative Region (http://sc.chp.gov.hk/gb/www. chp.gov.hk/en/notifiable1/10/26/43.html). Accessed 17 March 2010.

104. Chu YW, et al. A blood isolate of Neisseria meningitidis showing reduced susceptibility to quinolones in Hong Kong. International Journal of Antimicrobial Agents 2007; 30: 94-95.

105. Kobayashi Y, et al. Trend of bacterial meningitis in children over a 13-year period (1966 through 1978) in Japan. An analysis based on studies in 127 institutions (author's translation). Japanese Journal of Antibiotics 1979; 32: 795-805.

106. Kobayashi Y, et al. Trend of bacterial meningitis in children over a 14 year period (1981 through 1994) in Japan- an analysis based on studies in 27 institutions. Kansenshogaku Zasshi 1997; 71: 1017-1024.

107. Kobayashi Y. Chemotherapy of purulent meningitis in children (author's translation). Japanese Journal of Antibiotics 1975; 28: 567-580.

108. Sunakawa K, et al. Trends in pediatric bacterial meningitis in Japan (2003-2004) Kansenshogaku Zasshi $2006 ; 80$ : 27-38.

109. Sunakawa K. Analysis by questionnaire survey concerning example such as purulent meningitis and severe infectious diseases-relation among patient background factor, sequelae, and infecting organism. Japanese Journal of Antibiotics 2006; 59: 152-164.

110. Sakata H. A study of bacterial meningitis in Hokkaido between 1999 and 2003. Kansenshogaku Zasshi 2005; 79: $680-687$.

111. Sunakawa K, et al. The trend of childhood bacterial meningitis in Japan (2000-2002). Kansenshogaku Zasshi 2004; 78: 879-890.

112. Sunakawa K, et al. The trend of childhood bacterial meningitis in Japan (1997.7-2000.6) Kansenshogaku Zasshi 2001; 75: 931-939.
113. Kuriki M, et al. Acute encephalitis and bacterial meningitis in children in Aichi Prefecture (1984-1993) Nippon Koshu Eisei Zasshi 1995; 42: 338-345.

114. Taneda Y, Iwai N, Nakamura H. Clinical features and evaluation of initial antibiotic treatment in 125 cases with purulent meningitis in infancy and childhood. Japanese Journal of Antibiotics 1991; 44: 303316.

115. Uehara S, et al. Epidemiology of Haemophilus influenzae meningitis among infants and children in Japan: Comparison with incidences of bacterial meningitis. Nihon Shonika Gakkai Zasshi 1998; 102: 656665.

116. Haruta T. Meningococcal disease. Nippon Rinsho $2003 ; 61: 335-338$.

117. Kitamura K, Ihara T, Kamiya H. Bacterial meningitis in infants and children in Mie Prefecture Japan (1983-1993). Nihon Shonika Gakkai Zasshi 1996; 100: 45-48.

118. Kinoshita S, et al. A study of childhood purulent meningitis in Nagasaki Prefecture. I. Incidence and epidemiology. Nihon Shonikagakkai Zasshi 1993; 97 : 45-49.

119. Fujii R, et al. Trends in childhood bacterial meningitis in Japan (1979-1984). Part 1. On the causative organisms. Kansenshogaku Zasshi 1986; 60: 592-601.

120. Fujii R, Hiraiwa M, Kobayashi Y. The trend in childhood bacterial meningitis in Japan (1979-1984). Part 2. On the prognosis. Kansenshogaku Zasshi 1987; 61: 849-857.

121. Ishihara M, et al. Hospital-based study of the prognostic factors in adult patients with acute communityacquired bacterial meningitis in Tokyo, Japan. Internal Medicine 2009; 48: 295-300.

122. Chiba N, et al. Rapid detection of eight causative pathogens for the diagnosis of bacterial meningitis by real-time PCR. Journal of Infection and Chemotherapy 2009; 15: 92-98.

123. Horino T, et al. Meningococcemia without meningitis in Japan. Internal Medicine 2008; 47: 1543-1547.

124. Health Science Research Database. Meningococcal meningitis. Week 23, $2001 \mathrm{http}: / /$ mhlw-grants.niph. go.jp/niph/search/NIDD00.do. Accessed 30 April 2010 .

125. Takahashi H, et al. Characterization of Neisseria meningitidis isolates collected from 1974 to 2003 in Japan by multilocus sequence typing. Journal of Medical Microbiology 2004; 53: 657-662.

126. Tanaka $\mathbf{H}$, et al. Isolation of Neisseria meningitidis from healthy persons in Japan. Kansenshogaku Zasshi 2005; 79: 527-533.

127. Kim KH, et al. The causative organisms of bacterial meningitis in Korean children, 1986-1995. Journal of Korean Medical Science 1998; 13: 60-64.

128. Lee HJ. Epidemiology of systemic Haemophilus influenzae disease in Korean children. Pediatric Infectious Disease Journal 1998; 17: S185-S189.

129. Kim JS, et al. Incidence of Haemophilus influenzae type $b$ and other invasive diseases in South Korean children. Vaccine 2004; 22: 3952-3962. 
130. Choo KE, et al. Pyogenic meningitis in hospitalized children in Kelantan, Malaysia. Annals of Tropical Paediatrics 1990; 10: 89-98.

131. Lyn P, Pan Fui Lin. Management and outcome of childhood meningitis in east Malaysia. Medical Journal of Malaysia 1988; 43: 90-96.

132. ProMED mail. PRO/EDR $>$ Meningitis, meningococcal-Malaysia: (ME,PG) susp, RFI. 14 May 2009: 20090514.1812. (http://www.promedmail.org). Accessed 25 November 2010.

133. Gopez I, et al. Meningococcal disease outbreak in San Jose, Sipalay, Negros Occidental. Philippine Journal of Microbiology and Infectious Diseases 1991; 20: 17-22.

134. Lupisan SP, et al. Invasive bacterial infections of children in a rural province in the central Philippines. American Journal of Tropical Medicine and Hygiene 2000; 62: 341-346.

135. Gatchalian SR, et al. Bacterial and viral etiology of serious infections in very young Filipino infants. Pediatric Infectious Disease Journal 1999; 18: S50-S55.

136. Abucejo-Ladesma E, et al. Serious communityacquired paediatric infections in rural Asia (Bohol Island, Philippines): bacterial meningitis in children less than 5 years of age. Scandinavian Journal of Infectious Disease 2007; 39: 983-989.

137. Sutinen J, et al. Etiology of central nervous system infections in the Philippines and the role of serum C-reactive protein in excluding acute bacterial meningitis. International Journal of infectous Disease. 1998-1999; 3: 88-93.

138. Santana RT, et al. Clinical and laboratory profile of bacterial meningitis in Filipinos: six-year review. Journal of Tropical and Geographical Neurology 1992; 2: 151-156.

139. Chan YC, et al. Adult community acquired bacterial meningitis in a Singaporean teaching hospital. A seven-year overview (1993-2000). Singapore Medical Journal 2002; 43: 632-636.

140. Oh H, et al. Meningococcal infection in Singapore 1981-2000: clinical spectrum (abstract 61.024). In: Program and abstracts of the 10th International Conference on Infectious Diseases. Singapore, 2002, p. 145.

141. Lee YS, et al. Invasive Haemophilus influenzae type b infections in Singapore children: a hospital-based study. Journal of Paediatrics and Child Health 2000; 36: 125-127.

142. Lim KW, Cheng HK. Bacterial meningitis-a four year survey in a paediatrics unit. Annals of the Academy of Medicine, Singapore 1989; 18: 649-654.

143. Low PS, et al. Meningitis in Singapore infants and children. Journal of the Singapore Paediatric Society 1984; 26 : 150-154.

144. Nadarajah M. Bacterial meningitis-a five year review 1975-1979. Annals of the Academy of Medicine, Singapore 1981; 10: 11-13.

145. Anon. Meningococcal disease caused by N. meningitidis serogroup W135. Epidemiological News Bulletin Singapore $2001 ; 27$ : 55-56.
146. World Health Organization. Meningococcal disease, serogroup W135 (update). Weekly Epidemiological Record 2001; 13; 76: 213-214.

147. Wang CH, Lin TY. Invasive Haemophilus influenzae diseases and purulent meningitis in Taiwan. Journal of the Formosan Medical Association 1996; 95: 599-604.

148. Liu CC, et al. Bacterial meningitis in infants and children in southern Taiwan: emphasis on Haemophilus influenzae type B Infection Journal of the Formosan Medical Association 1993; 92: 884-888.

149. Chang CC, et al. Culture-proven bacterial meningitis in elderly patients in southern Taiwan: clinical characteristics and prognostic factors. Acta Neurologica Taiwanica 2006; 15: 84-91.

150. Chang WN, et al. Changing epidemiology of adult bacterial meningitis in southern Taiwan: a hospitalbased study. Infection 2008; 36: 15-22.

151. Tsai MH, et al. Bacterial meningitis in young adults in Southern Taiwan: clinical characteristics and therapeutic outcomes. Infection 2006; 34: 2-8.

152. Lu CH, Chang WN, Chang HW. Adult bacterial meningitis in Southern Taiwan: epidemiologic trend and prognostic factors. Journal of the Neurological Sciences $2000 ; 182$ : 36- 44.

153. Tang LM, et al. Acute bacterial meningitis in adults: a hospital-based epidemiological study. QJM: Monthly Journal of the Association of Physicians 1999; 92: 719-725.

154. Huang CR, et al. Community-acquired spontaneous bacterial meningitis in adult diabetic patients: an analysis of clinical characteristics and prognostic factors. Infection 2002; 30: 346-350.

155. Fang CT, et al. Microbiologic features of adult community-acquired bacterial meningitis in Taiwan. Journal of the Formosan Medical Association 2000; 99: 300-304.

156. Chang YC, et al. Risk factors analysis for early fatality in children with acute bacterial meningitis. Pediatric Neurology 1998; 18: 213-217.

157. Hsueh PR, et al. Re-emergence of meningococcal disease in Taiwan: circulation of domestic clones of Neisseria meningitidis in the 2001 outbreak. Epidemiology and Infection 2004; 132: 637-645.

158. Liu DP, et al. Prevalence of nasopharyngeal meningococcal carriers among newly enlisted military recruits in Taiwan. Epidemiology Bulletin 2006; 22: 54-74.

159. Taiwan CDC. Notifiable Infectious Disease Statistics System (http://nidss.cdc.gov.tw/SingleDisease. aspx? $\mathrm{dt}=2 \& \mathrm{dc}=1 \&$ disease $=0360 \& \mathrm{~d}=3 \& \mathrm{i}=\mathrm{all} \& \mathrm{~s}=$ determined_cnt\&RK=Y). Accessed 26 March 2010.

160. Yang CY, et al. Antigenic diversity of Neisseria meningitidis isolated in Taiwan between 1995 and 2002. Scandinavian Journal of Infectious Disease 2006; 38: 273-280.

161. Lin JC, et al. Meningococcal meningitis in Taiwan: clinical survey [in Chinese]. Journal of Internal Medicine Taiwan 2000; 11: 16-12.

162. Thisyakorn U, Chopitayasunondh T, Nimmannitya S. Meningococcal infections in children. Journal 
of the Pediatric Society of Thailand 1985; 24: 8-10.

163. Pancharoen C, Thisyakorn U. Meningococcal infection in children. Journal of Infectious Disease and Antimicrobial Agents 1998; 15: 55-58.

164. Chotmongkol V, Techoruangwiwat C. Community acquired-bacterial meningitis in adults. Southeast Asian Journal of Tropical Medicine and Public Health 2000; 31: 506-508.

165. Khwannimit B, Chayakul P, Geater A. Acute bacterial meningitis in adults: a 20 year review. Southeast Asian Journal of Tropical Medicine and Public Health 2004; 35: 886-892.

166. World Health Organization. WHO Vaccine Preventable Diseases Monitoring System. Immunization schedules by antigen, selection centre (http://apps. who.int/immunization_monitoring/en/globalsummary/ ScheduleSelect.cfm) Accessed on 17 August 2010.

167. Robbins JB, et al. Meningococcal meningitis in sub-Saharan Africa: the case for mass and routine vaccination with available polysaccharide vaccines. Bulletin of the World Health Organization 2003; 81: 745-750.

168. Korean Pediatric Society. The Korean Pediatric Society Immunization Guideline, 6th edn, 2008.
169. Kabra SK, et al. Bacterial meningitis in India: an IJP survey. Indian Journal of Pediatrics 1991; 58: 505-511.

170. Mirdha BR, Gupta U, Bhujwala RA. Latex agglutination test: an adjunct to the laboratory diagnosis of pyogenic bacterial meningitis. Indian Journal of Pediatrics 1991 ; 58: 521-524.

171. Peltola H. Spectrum and burden of severe Haemophilus influenzae type b diseases in Asia. Bulletin of the World Health Organization 1999; 77: 878-887.

172. Bravo LC; Asian Strategic Alliance for Pneumococcal Disease Prevention (ASAP) Working Group. Overview of the disease burden of invasive pneumococcal disease in Asia. Vaccine 2009; 27: 7282-7291.

173. Tikhomirov E, Santamaria M, Esteves K. Meningococcal disease: public health burden and control. World Health Statistics Quarterly 1997; 50: 170-177.

174. Shetty S, et al. A systematic review and critical evaluation of invasive Haemophilus influenzae type B disease burden studies in Asia from the last decade: lessons learned for invasive bacterial disease surveillance. Pediatric Infectious Diseases Journal 2010; 29: 653-661.

175. World Health Organization. Control of epidemic meningococcal disease. WHO practical guidelines, 2nd edn. WHO/EMC/BAC/98.3. 